\title{
FOXO Transcription Factors as Potential Therapeutic Targets in Neuroblastoma
}

\author{
Michael J. Ausserlechner1,3, Judith Hagenbuchner2,3, Stefan Fuchs', \\ Kathrin Geiger ${ }^{3}$ and Petra Obexer ${ }^{2,3}$ \\ Medical University Innsbruck, \\ ${ }^{1}$ Department of Pediatrics II, \\ ${ }^{2}$ Department of Pediatrics IV, \\ ${ }^{3}$ Tyrolean Cancer Research Institute, \\ Austria
}

\section{Introduction}

The hallmark of cancer cells is deregulated growth, inhibition of differentiation, and delay or blockage of programmed cell death. Tumor cells that are independent of extra- and/or intracellular regulatory mechanisms due to mutations in proto-oncogenes and tumor suppressors acquire the ability of uncontrolled proliferation and invasion into other tissues. FOXO (FOXO1, FOXO3, FOXO4, FOXO6) transcription factors control apoptosis, stress resistance and longevity in mammalian cells. Their activity and subcellular localization is regulated by phosphorylation on conserved serine/threonin residues via protein kinase $B$ (PKB) and stress-induced kinases. Hyperactivation of PKB contributes to the inactivation of FOXO3 and predicts poor outcome for neuroblastoma patients. Depending on their posttranslational modifications and cellular context FOXO transcription factors exert diverse functions thereby either inducing cell death but also cell survival and resistance to environmental stress. Although FOXO transcription factors share the same DNA binding motive and seem to have overlapping functions, knock out animals for single FOXO family members show different defects: Whereas FOXO1 knock-out mice die during embryonic development due to defective vasculature, FOXO3 and FOXO4 knock out mice show a mild phenotype. However, conditional triple-knock-out mice provide evidence that FOXO1, FOXO3 and FOXO4 are critically involved in the maintenance of the hematopoietic stem cell population and the regulation of endothelial cell homeostasis. Consistent with their putative role as tumor suppressors, in cultured neuroblastoma cells the activation of FOXO3 triggers the intrinsic death pathway and induces programmed cell death via induction of the proapoptotic BH3-only proteins BCL2L11/Bim and PMAIP1/Noxa. Surprisingly, in neuroblastoma cells FOXO3-mediated cell death depends on the accumulation of reactive oxygen species (ROS). Activation of FOXO3 also causes the repression of the apoptosisinhibitor protein Survivin and determines sensitivity of neuroblastoma cells to DNAdamaging chemotherapeutic agents. More recently it was shown that beside its function as a tumor suppressor FOXO3 might also facilitate cancer cell survival under certain circumstances. In other tumor types FOXO3 also induces detoxification and stress resistance 
thereby contributing to tumor stem cell renewal and protection of cancer cells from eradication during chemotherapy. In this respect FOXO3 was recently shown to be essential for the maintenance of leukemia initiating cells in chronic myeloid leukemia and to confer therapy resistance in leukemia cells. Active FOXO3 facilitates metastasis through activation of matrix metalloproteinases, leads to lymph node positivity and predicts poor survival in breast carcinoma. In this article we will therefore review the current knowledge of FOXO transcription factors, their "Janus-faced role" in tumor cell survival and drug sensitivity and discuss whether FOXO3 might be an interesting target for therapeutic intervention in neuroblastoma.

\section{A general overview on FOXOs}

The forkhead transcription factor family consists of more than 100 members, which are important in various processes including development, cellular differentiation, proliferation, cell cycle arrest, cell death, tumor suppression, stress resistance and metabolism (Carlsson and Mahlapuu 2002). In mammals four members of the forkhead transcription factor class $\mathrm{O}$ (FOXO) family are known, named FKHR/FOXO1, FKHRL1/FOXO3, AFX/FOXO4 and FOXO6 (Katoh and Katoh 2004). FOXO transcription factors are homologs of the Caenorhabditis elegans protein DAF-16 which regulates the life-span of C. elegans (Lin et al, 1997) and were first discovered through the cloning of chromosomal breakpoints associated with cancer. Since the chromosomal translocation disrupted the FOXO-DNA-binding domain in the oncogenic fusion protein it was proposed that all three FOXOs act as tumor suppressors. FOXO proteins function primarily as transcription factors in the nucleus and bind as monomers to a consensus DNA sequence with a DNA-binding "winged-helix" domain, also called forkhead box, a 110 amino acid region in the central part of the protein (Weigelt et al, 2001). FOXO factors bind to the DNA-binding motif TTGTTTAC, TT(G/A)TTTTC and (C/A)(A/C)AAA(C/T)AA (Obsil and Obsilova 2010; Furuyama et al, 2000). Bioinformatics analyses showed that a large set of genes contain FOXO-binding sites in their promoter region (Xuan and Zhang 2005). FOXO proteins act as potent transcriptional activators, but gene array analyses indicate that FOXOs can also act as transcriptional repressors (Ramaswamy et al, 2002).

To specify the diverse functions of FOXO transcription factors, knock-out mice were generated. These approaches revealed distinct but overlapping roles of FOXO members in mammals. FOXO1 null mice die during embryonic development due to defective vascularization (Hosaka et al, 2004). In vitro experiments further suggest that FOXO1 is important for endothelial cells to respond to vascular endothelial growth factor (VEGF). FOXO3 null mice are viable but exhibit an age-dependent female infertility as a consequence of abnormal follicular activation leading to total depletion of ovarian follicles (reviewed in (Arden 2008a)). Furthermore FOXO3 null mice show defects in the glucose uptake (Castrillon et al, 2003). This implies a role of FOXO factors in glucose metabolism. In lymphoid organs, FOXO3 is the predominant FOXO member and its deficiency leads to lymphoproliferation and widespread organ inflammation. FOXO4 null mice are viable and show no overt phenotype (Hosaka et al, 2004). Since all three FOXO transcription factors recognize the same DNA consensus sequence, the three family members seem to have overlapping functions. Since there is possible functional redundancy between the family members, a triple knock-out mouse with conditional deletions of FOXO1, FOXO3 and FOXO4 was developed. These animals show abnormalities in lymphoid development and a 
defect in the long-term repopulating activity of the bone-marrow stem cells. Additionally, these mice have a significant reduction in their long-term hematopoietic stem cell population and a decrease in a subset of genes, which are involved in detoxification and prevention of oxidative stress (Tothova et al, 2007b). This suggests that FOXOs play a major role in the response to oxidative stress (Arden 2008b). Furthermore the inactivation of all three FOXO transcription factors results in lymphoblastic thymic lymphomas, leukemias and widespread hemangiomas (Paik et al, 2007). Since these animal models support a critical role of FOXOs in the homeostasis of the stem cell population, deregulation of FOXOs might contribute to the development of various malignancies, among them human neuroblastoma.

\section{Regulation of FOXOs by survival and stress signaling}

FOXO proteins are post-translationally regulated by phosphorylation, acetylation or ubiquitination via different signaling pathways. These modifications determine the cellular localization of FOXO proteins and the interaction with binding partners. In the absence of growth factors, FOXO3 localizes to the nucleus. Binding of growth factors such as insulin, insulin-like-growth factor (IGF) or neurotrophic factors (nerve growth factor (NGF), brainderived-neurotrophic-factor (BDNF), neurotrophin-3, -4 (NT-3, -4)) to their cognate receptors induce a signaling cascade that leads to the activation of phosphatidylinositol-3kinase (PI3K) and the production of phosphoinositol-3-phosphate (PIP3). The second messenger PIP3 serves as an adapter molecule for pleckstrin homology (PH)-domain containing proteins at the cytoplasma membrane, such as the protein kinase $B(P K B)$. The molecular interaction of these proteins at the membrane induces their (auto)phosphorylation and activation (reviewed in (Coffer and Burgering 2004)). When activated, PKB phosphorylates FOXO transcription factors on three highly conserved sites (e.g. FOXO3 on threonin-32, serine-253, serine-315), one located in the forkhead domain, one at the $\mathrm{N}$-terminal and one at the C-terminal site. Phosphorylation by PKB masks the nuclear localization sequence (NLS) of FOXO3 and impedes DNA-binding. Furthermore PKB phosphorylation prevents the interaction with the transcriptional co-activator p300/CBP and promotes binding of FOXO proteins to 14-3-3. Following this binding FOXO3 undergoes a conformational change that results in the exposure of a nuclear export sequence (NES) on its C-terminal site and causes the export of FOXO3 into the cytoplasm (Biggs et al, 1999; Brunet et al, 1999). This conformational change allows FOXO3 to interact with Exportin/Crm1 and Ran, which leads to its export into the cytoplasm via the nuclear pore complex, repression of its transcriptional activity and to ubiquitin-mediated proteasomal degradation. Nuclear re-import is prevented due to masking of its NLS by 14-3-3 proteins (Rena et al, 2002). The PI3K-PKB signaling pathway is negatively regulated by phosphatases such as PTEN (Yamada and Araki 2001) that degrade PIP3 and thereby abrogate this signaling cascade. Loss of PTEN is frequently observed in carcinomas (Li et al, 1997) and hematologic malignancies (Sakai et al, 1998). The overexpression of growth factors that activate the PI3K or mutations in its regulatory subunits also result in hyperactivation of the PI3K-PKB pathway. PKB is dysregulated in a variety of cancers such as neuroblastoma (Opel et al, 2007). In addition to PKB, also the serum and glucocorticoid-inducible kinase (SGK) and the cyclin-dependent-kinase-2 (CDK2) phosphorylate FOXOs at distinct sites, which triggers their export from the nucleus (reviewed in (Coffer and Burgering 2004)). Other kinases which phosphorylate FOXO3 are the serine/threonine kinase CK1 (Rena et al, 
2002) and the dual tyrosine phosphorylated regulated kinase 1 (DYRK1), which belongs to the MAP kinase family (Woods et al, 2001).

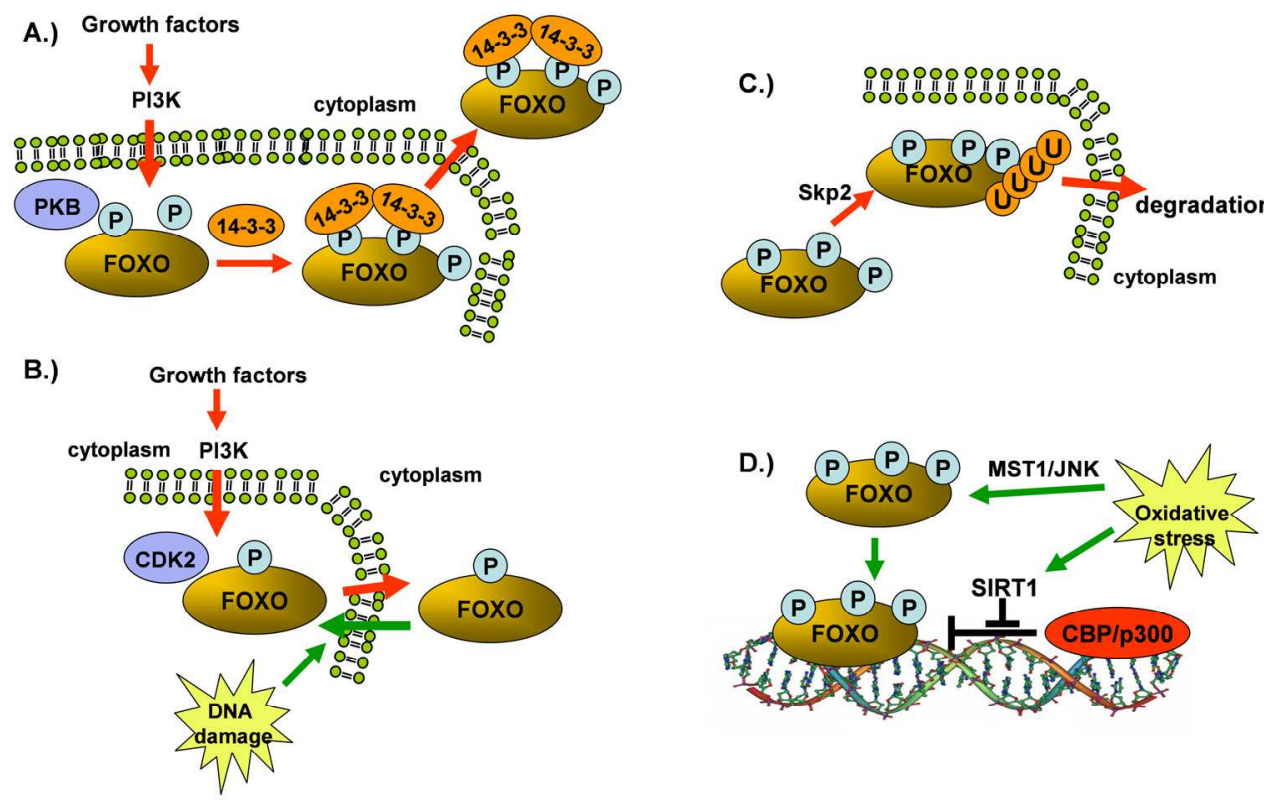

Growth factors such as IGF-1 lead to activation of PKB and CDK2 via PI3K-dependent pathways resulting in phosphorylation of FOXOs at distinct sites. A) PKB-mediated phosphorylation induces the binding of the chaperone protein 14-3-3 and subsequent export into the cytoplasm. B) CDK2-mediated phosphorylation also leads to cytoplasmic localization. Upon DNA-damage the CDK2-triggered phosphorylation activates FOXOs. C) Skp2 of the SCF-E3 ligase complex interacts with and ubiquitylates FOXO1. D) In response to oxidative stress FOXOs translocate into the nucleus as a consequence of direct JNK or MST1 phosphorylation. Acetylation of FOXOs by CBP/p300 inhibits their transcriptional activity. Under conditions of oxidative stress this effect can be overcome by the deacetylase SIRT1. Red arrows indicate negative regulation, whereas green arrows indicate positive regulation.

Fig. 1. Regulation of FOXO proteins in response to external and internal stimuli.

In contrast, oxidative and genotoxic stress results in FOXO3 phosphorylation by c-Jun Nterminal kinase (JNK) and by mammalian sterile 20-like kinase 1 (MST1), which forces translocation of FOXO transcription factors from the cytoplasm to the nucleus even in the presence of growth factor signaling (Sunters et al, 2006; Lehtinen et al, 2006; Essers et al, 2004). Additional posttranslational modifications modify FOXO activity, such as acetylation of lysines in the forkhead domain by $\mathrm{CBP} / \mathrm{p} 300$ or deacetylation by the protein deacetylase sirtuin-1 (SIRT1). The interaction with SIRT1 modulates the transcriptional function of FOXO3 resulting in the inhibition of FOXO3-induced expression of pro-apoptotic genes and the enhanced expression of genes involved in cell cycle regulation, DNA-repair and stress resistance (Brunet et al, 2004). Deacetylation of FOXO3 preferentially enhances the expression of genes that regulate cell cycle arrest, DNA-repair and stress resistance, which finally induces longevity instead of death inducing factors (Brunet et al, 2004; FurukawaHibi et al, 2002). An additional mode of FOXO regulation is its proteasomal degradation, 
which irreversibly shuts down FOXO activity (Hu et al, 2004). Ubiquitination by ubiquitinligase Skp2 or de-ubiquitination by USP7 adds an additional level of control (van der Horst et al, 2006). Poly-ubiquitination depends on phosphorylation of FOXOs by PKB; Skp2 directly interacts with FOXO1 after PKB-specific phosphorylation at serine-253. Deacetylation by SIRT1 and SIRT2 on the lysine residues K242, K259, K290 and K569 facilitates Skp2-mediated FOXO3 ubiquitination and proteasomal degradation (Wang et al, 2011). Furthermore, FOXO proteins have been shown to cooperate with cofactors such as Smad3/4 and the transcription factor p53 as well as with nuclear androgen-, glucocorticoid- and retinoic acid receptors (reviewed in (Calnan and Brunet 2008; van der Vos and Coffer 2008)).

\section{Physiological functions of FOXOs}

FOXO transcription factors control the expression of various genes which are involved in cell proliferation, cell survival, DNA repair and apoptosis. Cell proliferation is controlled by FOXO3 via inducing the expression of cell cycle breaks such as the Cdk inhibitor (CKI) $\mathrm{p} 27 \mathrm{Kip} 1$ and the retinoblastoma family member $\mathrm{p} 130$. Both proteins are negative regulators of cell cycle progression and induce cell cycle arrest in the G1 phase (Kops et al, 2002b; Dijkers et al, 2000b). Another FOXO3-regulated CKI p21Cip1 which is activated in response to tumorgrowth factor $\beta$ (TGF $\beta$ ) induces cell cycle arrest at G1. FOXO3 can directly bind to the transcription factors Smad3 and Smad4 and the resulting complex further binds to a forkhead and a smad binding element within the p21 ${ }^{\mathrm{Cip} 1}$ promoter leading to increased p21 ${ }^{\text {Cip1 }}$ expression (Seoane et al, 2004). Beside activation of cell cycle inhibitors FOXO3 can also induce cell cycle arrest by repressing the G1 cell cycle activators cyclin D1 and D2 (Schmidt et al, 2002; Fernandez et al, 2004). FOXO transcription factors have also been implicated in the control of G2-M transition and in exit from telophase. In particular FOXO3 regulates the expression and degradation of cyclin B and of Polo-like kinase (Alvarez et al, 2001) and the DNA damage-inducible protein 45 (Gadd45a). Under low stress conditions FOXO3 promotes DNA repair in a Gadd45a dependent mechanism, whereas under high levels of stress FOXO3 induces cell death (Furukawa-Hibi et al, 2002; Tran et al, 2002). Stress stimuli like hypoxia, ionizing radiation, oxidants, UV light or growth factor withdrawal strongly induce Gadd45a. Gadd45a is also involved in cellular mechanisms like G2-M cell cycle progression, genomic stability, nucleotide excision repair, apoptosis and signaling through MAP kinase and JNK (Lal and Gorospe 2006). Similar to PKB activity, the expression level, phosphorylation and subcellular localization of FOXO3 changes during the cell cycle, which is in part regulated by the phosphatase Cdc25A (Leisser et al, 2004). Importantly, FOXOs may also protect cells against reactive oxygen species (ROS) by inducing the two scavenger proteins superoxide dismutase (SOD2/MnSOD) and CAT/Catalase and may even induce therapy resistance by activating the multi-drug resistance gene MDR1 (Hui et al, 2008a; Kops et al, 2002a).

FOXOs not only control proteins involved in cell cycle progression but also regulate proand anti-apoptotic genes, particularly in neurons and hematopoietic cells. Two proapoptotic proteins whose expression is induced by FOXO3 are the $\mathrm{BH} 3$-only proteins PMAIP1/Noxa and BCL2L11/Bim (Dijkers et al, 2000a; Obexer et al, 2007). The Bim promoter contains two conserved forkhead response elements (FHRE). Binding of FOXO3 to these elements results in apoptotic cell death in sympathetic neurons and neuroblastoma cells (Gilley et al, 2003; Obexer et al, 2007). The induction of the BH3-only protein Noxa leads in neuroblastoma cells to apoptosis via the intrinsic death pathway (Obexer et al, 
2007). FOXO3 also regulates the transcription of genes which are involved in the extrinsic death pathway, like Fas ligand (FASLG) (Brunet et al, 1999) and tumor necrosis factorrelated apoptosis inducing ligand (TRAIL). FOXO3 binds directly three FHRE within the regulatory region of the FASLG promoter and a novel binding site in the sequence of the TRAIL promoter (Modur et al, 2002). Under conditions of oxidative stress FOXO3 strongly induces the expression of the transcriptional repressor B-cell/lymphoma 6 (BCL6). BCL6 represses the anti-apoptotic protein BCL2L1/Bcl-xL which contains a STAT/BCL6 binding site within its promoter (Tang et al, 2002). Via this indirect regulation of $\mathrm{Bcl}-\mathrm{xL}$, FOXO3 changes the balance of pro- and anti-apoptotic proteins from survival to cell death induction. Interaction of FOXO factors with other transcription factors influences the transcriptional activity of FOXO proteins and determines the regulation of its target genes. $\beta$-catenin directly interacts with FOXO factors and thereby increases the expression of MnSOD. This leads to a shift from apoptosis regulating genes to oxidative stress detoxifying genes, which results in longevity (Essers et al, 2005). Another transcription factor which regulates FOXO3 activity is p53. Binding of p53 to FOXO3 under low stress conditions prevents induction of pro-apoptotic Bim and the transcriptional repressor BCL6, whereas expression of cyclin G2 and p27Kip1 are not affected. By modifying the target gene spectrum of FOXO3, the p53/FOXO3 complex induces cell cycle arrest instead of apoptosis (Miyaguchi et al, 2009).

Taken together, FOXO3 is involved in various cell-type specific, cellular functions. Depending on its posttranslational modifications such as phosphorylation, acetylation, ubiquitination or interaction with other transcription factors, FOXO factors regulate even opposite effects, like cell cycle arrest, apoptosis induction or even induction of longevity.

\section{Regulation of FOXOs in neural stem cells and neuronal cells}

Neural stem cells are the self-renewing population that is important for proper generation of neurons, astrocytes and oligodendrocytes in the developing but also in the adult brain where they play a critical role for learning and for the brain-homeostasis during aging. They participate in memory, behavior, and brain injury repair.

The insulin/IGF1/PI3K/PKB/FOXO signaling controls neural stem cell proliferation. Neural stem cells that overexpress PKB show an enhanced proliferation and a reduced capacity to differentiate (Peltier et al, 2007). In addition to maintaining the replicatorypotential of hematopoietic stem cells (Tothova et al, 2007b) it was recently shown that FOXO3 knockout mice have fewer neural stem cells than wildtype mice and that neural stem cells isolated from FOXO3 $\%$ mice had reduced self-renewal capacity and showed impaired differentiation into different neural lineages. FOXO3 knockout mice and mice with conditional deletion of FOXO3, FOXO4 and FOXO1 in the brain show an increased brain size. Furthermore their neural stem cells have enhanced rates of entry into the cell cycle suggesting that FOXO3 is important to maintain the relative quiescence of neural stem cells and prevents their premature exhaustion (Renault et al, 2009; Paik et al, 2009). One FOXO3 target that might be critical for these neuronal abnormalities is abnormal spindle-like microcephaly-associated (Aspm) which is repressed by FOXO1 and FOXO3. This protein limits neural progenitor expansion during development and prevents early exhaustion of the adult neural stem cell pool (Bond et al, 2002). Adult neurogenesis relies on adult mitotic neural stem cells. Activation of $\mathrm{dFOXO}$ in Drosophila causes the elimination of these neural stem cells during the development via Caspase-dependent cell death (Siegrist et al, 2010). In 
adult neural stem cells that lack FOXO1, FOXO3 and FOXO4 due to gene deletion, increased levels of reactive oxygen species (ROS) are detected. This correlates with altered expression of the detoxifying enzymes peroxiredoxin, glutathione peroxidase-1 and SESN3/sestrin-3. Since neuronal cells in particular depend on the thiol-redoxin system to defend themselves against ROS, regulation of these enzymes by FOXOs is critical for neuronal survival. FOXOs may therefore contribute to the self-renewal of neural stem cells by reducing ROSaccumulation, which is further supported by the observation that impaired self-renewal in the FOXO1/3/4 triple knock out neural stem cells can be rescued by the antioxidant $\mathrm{N}$ acetyl cysteine (NAC) or the expression of SESN3 (Paik et al, 2009).

Genome wide microarray analysis from $\mathrm{FOXO} 3^{-/}$and $\mathrm{FOXO}^{+/+}$neural stem cells from young adult mice revealed that FOXO3 regulates the neural stem cell pool by inducing genes that on one side promote quiescence and prevent premature differentiation and on the other side are involved in oxidative stress resistance and in control of glucose metabolism. When comparing the FOXO3-target genes with genes necessary during the process of aging in human and mouse brains, Renault et al observed a correlation between FOXO3-regulated genes and aging-regulated genes. This suggests that FOXO3 plays a critical role in the regulation of nerve stem cell homeostasis and may also be critical for brain-aging in mammals (Renault et al, 2009). The FOXO-dependent transcriptome of neural stem cells has little in common with the transcriptome of other cell types such as hematopoietic stem cells or endothelial cells. This indicates that FOXO transcription factors exert cell-type specific functions (Tothova et al, 2007a; Paik et al, 2007; Paik et al, 2009).

MicroRNAs have recently emerged as key regulators of embryonic and adult stem cells (Arnold et al, 2011). FOXO3 binds to a site in the first intron and thereby regulates the microRNA gene cluster miR-106b 25 consisting of miR-106b, miR-93 and miR-25 in primary cultures of neural stem/progenitor cells isolated from adult mice (Brett et al, 2011). Expression of this microRNA gene cluster promotes proliferation in self-renewal conditions and increased generation of new neurons in differentiation conditions. Therefore FOXO3 also regulates miRNAs which are necessary for the maintenance of adult stem cells and for the homeostasis of the neural stem cell pool during aging (Brett et al, 2011).

Similar to the hematopoietic system also during the development of the nerve system the effect of FOXO activation might completely differ between stem cells, progenitor cells and terminally differentiated cells. This has to be kept in mind when studying FOXO3 function in tumor cells that arise from different types of neuronal tumor stem cells, such as neuroblastoma. FOXO3 is expressed throughout the brain including hippocampal areas, cortex and cerebellum and may play a role during injuries that involve cerebral ischemia and oxidative stress (Chong et al, 2005). In primary cortical and cerebellar neurons NGF, NT-3 and -4, and IGF-1 mediate survival by inhibition of FOXO1 (Gan et al, 2005) and FOXO3 and its nuclear exclusion via the PI3K/PKB signaling pathway. Therefore during oxidative stress the inhibition of FOXO3 is necessary for the protective effect of trophic factors in neurons (Zheng et al, 2000; Zheng et al, 2002). High PKB-activity also accounts for neuroprotection in ischemic tolerance in hippocampal neurons (Yano et al, 2001) whereas a decreased PKB- and as a consequence thereof induced FOXO-activity mediates ischemiainduced cell death. Following ischemic brain injury FOXOs induce delayed neuronal apoptosis via induction of FASLG and the BH3-only protein Bim in hippocampal regions. Neurons can be rescued from this delayed apoptosis by sodium orthovanadate which increases PKB-activity and therefore inhibits FOXO-dependent death signals (Fukunaga et al, 2005). In neonatal mice FOXO3 expression is associated with the potential to promote 
cerebral hypoxic-ischemic injury (Pirianov et al, 2007) and the neuroprotective effects of estradiol during stroke are associated with inhibition of FOXO3 (Won et al, 2006). Stroke and reperfusion are associated with significant oxidative stress in neuronal cells and depending on the cell type, FOXO3 function may support survival or be detrimental. In neurons oxidative stress activates the tyrosine kinase c-Abl which in turn activates the protein kinase MST1 by phosphorylation at tyrosine-433. MST1 then phosphorylates serine209 in the DNA-binding domain of FOXO3, which disrupts FOXO3 interaction with 14-3-3 proteins that are essential for the export of FOXO3 from the nucleus. This induces the nuclear accumulation and activation of FOXO3 even in presence of inhibitory PKB signals. Increased interaction of MST1 and FOXO3 activates the MST1-FOXO3 signaling pathway finally leading to cell death in both primary cultured neurons and rat hippocampal neurons (Xiao et al, 2011). Interestingly, in Drosophila the activation of the JNK/FOXO signaling pathway leads to neuronal resistance to oxidative stress via the expression of Jafrac1 the fly homologue of peroxiredoxin II. Neurons are susceptible to oxidative damage because of their high levels of ROS production and relatively low levels of antioxidant enzymes. Therefore JNK/FOXO suppresses oxidative stress-induced lethality and extends life span in Drosophila (Lee et al, 2009).

\section{Are FOXOs tumor suppressor proteins or do they contribute to tumor development?}

As FOXO transcription factors were discovered through the cloning of chromosomal breakpoints which were associated with cancer it was proposed that FOXOs act as tumor suppressors. Consistent with their putative role as tumor suppressors, overexpression of FOXOs in cell lines causes cell cycle arrest or cell death. However, depending on posttranslational modifications these transcription factors also regulate detoxification and stress resistance thereby protecting tumor cells from eradication during chemotherapy (Calnan and Brunet 2008). The dual role of FOXOs will be discussed in the following chapters.

\subsection{Role of FOXO3 in cancer cell survival and in tumor stem cells}

Although FOXOs were first described as tumor suppressor proteins, emerging data also suggest that FOXO transcription factors, in specific FOXO3, may have a "dark side": FOXO3 was shown to support cancer development by protecting tumor cells against oxidative stress by inducing the enzyme MnSOD and PTEN-induced putative kinase-1 (Pink1) (Kops et al, 2002a; Lee et al, 2009; Mei et al, 2009). Deletion of Pink1 sensitizes cells to growth factor withdrawal-induced cell death therefore demonstrating the important role of FOXO3 for protecting cells against growth factor depletion and oxidative stress mediated apoptosis (Mei et al, 2009). Furthermore FOXO3 induces via a negative feedback loop PKB survival signaling in chronic myelogenous leukemia cells. The acquisition of chemoresistance against doxorubicin correlates with activation of FOXO3 and an enhanced PI3K/PKB signaling via induction of PIK3CA, the PI3K catalytic subunit p110alpha (Hui et al, 2008b). In addition FOXO3 promotes multi-drug resistance in chronic myelogenous leukemia cells by inducing MDR1, a plasma membrane P-glycoprotein that functions as an efflux pump for different anticancer drugs. FOXO3 directly binds and activates the MDR1-promoter and increases the MDR1 drug efflux potential. In response to doxorubicin treatment FOXO3 induces in an early response cell cycle arrest and cell death but prolonged exposure promotes the development of cells that are drug resistant due to FOXO3-induced expression of MDR1 
(Hui et al, 2008a). In such doxorubicin-resistant cells FOXO3 enhances PI3K/PKB signaling, but active PKB cannot induce the relocalization of FOXO3 from the nucleus to the cytoplasm suggesting that FOXO3 inactivation by PKB is hampered or that strong FOXO3 activating signals override inactivation by PKB. It is not clear, whether such cancer cells evolve by a selection process or whether a small, stem-cell like tumor cell population already exists which benefits from FOXO3 activation because of an already defined intrinsic "FOXO3stemness longevity program". However, in such drug-resistant cancer cells active FOXO3 does not induce apoptosis or cell cycle arrest but leads to tumor progression and the development of an aggressive phenotype. Such a correlation between FOXO3 activation and adverse disease is not only observed in leukemic tumor cells but also in other types of cancer. For example in invasive ductal breast carcinoma nuclear localization of FOXO3 correlates with lymph node positivity and predicts poor survival (Chen et al, 2010). More recently it was discovered that FOXO3 supports tumor cell invasion via induction of matrix metalloproteinase (MMP)-9 and MMP-13, both of which induce invasion and metastasis of solid tumors (Storz et al, 2009). FOXO3 may not only protect cells against oxidative stress but also prevent the detrimental effects of transitory hypoxia. FOXO3 attenuates the proapoptotic response to hypoxia mediated by HIF1 in breast cancer cells by inducing the transcriptional cofactor CITED-2 which in turn controls HIF1 via a negative feedback loop (Bakker et al, 2007). These data clearly support the notion that the tumor suppressor and apoptosis-inducer FOXO3 may even promote cancer progression and metastasis depending on cell type and cellular differentiation stage.

Recently it was shown, that FOXO3 critically regulates tumor stem cell maintenance in chronic myeloid leukemia (CML) which is characterized by the Bcr-Abl genetic abnormality. $\mathrm{Bcr}-\mathrm{Abl}$ induces the $\mathrm{PI} 3 \mathrm{~K} / \mathrm{PKB}$ signaling pathway which represses the transcriptional activity of FOXO3 in these cancer cells. One of the major problems of CML treatment is the small population of leukemia initiating cells which promote recurrence of the disease. Naka et al. could demonstrate that in these leukemia-initiating cell population FOXO3 localizes to the nucleus and promotes their maintenance and stress resistance (Naka et al, 2010). FOXO3 seems to be the most important regulator of hematopoietic stem cells as FOXO3 is essential for the maintenance of the hematopoietic stem cell pool. Depletion of FOXO3 in hematopoietic stem cells leads to a reduced number of colony-forming cells in long-term cocultures of bone marrow and stromal cells, an increase in ROS levels, a deficient repopulating capacity in serial transplantation assays, defective maintenance of quiescence and a higher sensitivity to cell cycle dependent myelotoxic agents such as 5-Fluorouracil (Miyamoto et al, 2007). These functions of FOXO3 in normal hematopoietic stem cells are apparently also important for the persistence of cancer stem cells in CML.

Neuroblastoma tumors are derived from embryonal neural stem cells in which FOXO3 may play an essential role in cell survival and replicative capacity similar to neural stem cells in the adult organism. Depending on the original cancer stem cell that gives rise to the tumor, FOXO3 regulation and function may differ explaining the phenomenon that some tumors respond well or even regress without chemotherapy, whereas others are highly resistant to high dose radiation and chemotherapy. Our own studies on neuroblastoma cells demonstrate that DNA-damaging chemotherapeutic drugs such as doxorubicin and etoposide which are also widely used for cancer therapy induce the accumulation of FOXO3 in the nucleus as determined via immunofluorescence analysis in SH-EP neuroblastoma cells expressing a wildtype FOXO3 allele (see Figure 2). FOXO3 induces programmed cell death in SH-EP/FOXO3 and NB15/FOXO3 cells (Obexer et al, 2007) but may also promote 
death resistance in neuroblastoma tumor cells after prolonged exposure of the cells to chemotherapeutic drugs (unpublished). In high stage neuroblastoma tumors it is frequently observed that almost no immune cells infiltrate the tumor tissue. The role of FOXO3 for immune-surveillance will be discussed in the next chapter.

A.)

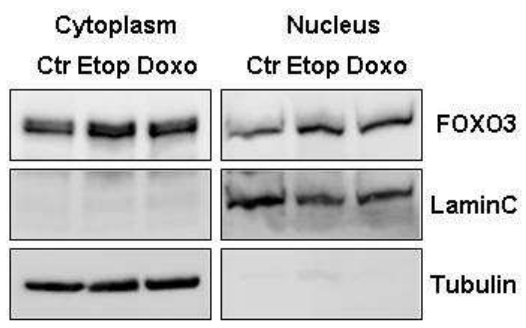

B.)
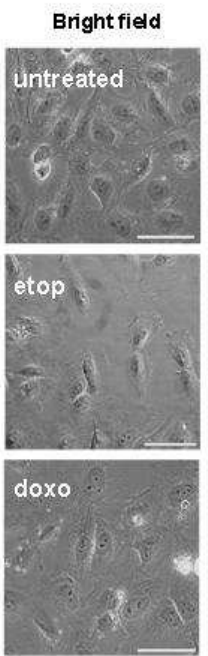

Hoechst
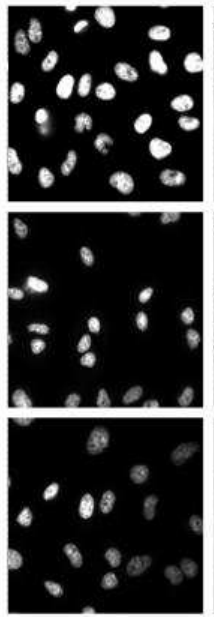

FITC - FOXO3
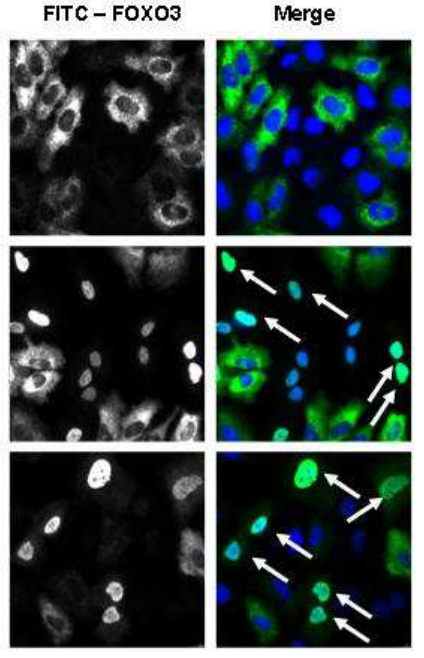

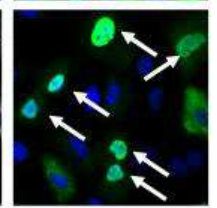

A) The localization of FOXO3 was demonstrated by immunoblot analysis of nuclear and cytoplasmic fractions of untreated, etoposide $(20 \mu \mathrm{g} / \mathrm{ml})$ or doxorubicin-treated $(0,25 \mu \mathrm{g} / \mathrm{ml}$, for 3 hours $) \mathrm{SH}$ $\mathrm{EP} / \mathrm{FOXO} 3$-wt cells expressing a wildtype FOXO3 allele. After etoposide and doxorubicin treatment FOXO3 accumulates in the nuclear fraction. Lamin A (nuclear protein) and Tubulin (cytoplasmic protein) were used as purification controls. B) Immunofluorescence analyses of SH-EP/FOXO3-wt cells reveal that in untreated cells FOXO3 localizes to the cytoplasm whereas in etoposide and doxorubicintreated cells (for 3 hours) FOXO3-FITC is mainly present in the nucleus. Arrows mark nuclei with FOXO3-FITC staining.

Fig. 2. Localization of FOXO3 after treatment with the chemotherapeutic agents doxorubicin (doxo) and etoposide (etop).

\subsection{FOXO3 represses immune function and immune surveillance}

One aspect of cancer biology that is often neglected by those who focus on signal transduction in cancer cells is the essential role of the immune system in eliminating malignant and precancerous cells. FOXO3 is also involved in this aspect of cancer development as it coordinates immune responses by inducing apoptosis in T-cells thereby 
maintaining T-cell homeostasis and T-cell activity (Pandiyan et al, 2004; Dejean et al, 2009). Morever FOXO3 is involved in the persistence of $\mathrm{CD}^{+}$memory T-cells (Riou et al, 2007). One hallmark of FOXO3 knockout mice is that they develop a multi-inflammatory disease involving the intestine and various other tissues (Lin et al, 2004). This is due to the fact that FOXO3 affects several different players of the immune system: FOXO3 is an essential transcriptional regulator of FoxP3 (Harada et al, 2010) and thereby controls the differentiation of naive T-cells into so-called regulatory T-cells (Treg). Tregs are important in confining the immune reaction and in preventing autoimmune disease. In cancer, however, these immunosuppressive T-cells also infiltrate tumors and repress the anti-cancer activity of cytotoxic T-cells. A deletion of Tregs during cancer therapy, e.g. by blocking FOXO3 could therefore boost the anti-tumor activity of the immune system. In addition it was shown that FOXO3 suppresses the expansion of antigen-specific effector T-cell populations (Wang et al, 2011) which might also hamper anti-cancer immunity. Also another branch of the immune system is significantly influenced by FOXO3: in stimulated dendritic cells, FOXO3 localizes to the nucleus and constrains the production of interleukin-6 and tumor necrosis factor (Dejean et al, 2009). Lack of FOXO3 in dendritic cells enhances T-cell viability and expansion thereby contributing to the pro-inflammatory phenotype. Importantly, in prostate cancer FOXO3 is highly expressed in tumor-associated dendritic cells and thereby induces a suppressive activity in the tumor-specific $\mathrm{CD} 8^{+} \mathrm{T}$-cell population. Repression of FOXO3 in dendritic cells using siRNAs upregulated the expression of co-stimulatory molecules and pro-inflammatory cytokines and enhanced the immune responses (Watkins et al, 2011). Silencing of FOXO3 in dendritic cells can be a strategy for the enhancement of anti-tumor immunity and also to overcome immune tolerance. It has not been investigated to date, whether FOXO3 is also involved in immune suppression in neuroblastoma. However, these recent publications imply that FOXO3 activity might rather support the progression of malignancies than preventing them due to its repressive function on the immune system.

\subsection{FOXO3 regulates programmed cell death and death sensitivity in neuroblastoma cells}

\subsubsection{A brief overview on cell death regulation}

Apoptosis plays a critical role in tumorigenesis and is a cellular process regulated either via membrane death receptors ("extrinsic pathway") or by the balance of pro- and antiapoptotic proteins of the BCL2-family at the mitochondria ("intrinsic pathway", see figure 3) (Coultas and Strasser 2003). In the "extrinsic" apoptosis pathway death ligands such as TRAIL and FASLG bind to their cognate receptors thereby inducing the formation of the so called "death inducing signaling complex" (DISC) which consists of the adaptor protein Fasassociated death domain (FADD) and Procaspase-8. In this complex Caspase-8 is activated via autocleavage.

The "intrinsic pathway" is triggered by developmental cues and intracellular stresses such as DNA-damage, growth factor withdrawal and anoikis. It is regulated at the level of mitochondria by the balance of pro- and anti-apoptotic BCL2-proteins, which is also termed BCL2-rheostat (Cory and Adams 2002). The BCL2 protein family is divided into two subgroups: one is the so called "multidomain" family that consists of pro-apoptotic members such as BAX and BAK1/Bak and pro-survival proteins e.g. BCL2, Bcl-xL, BCL2L2/Bcl-w and MCL1. The other subgroup is the BH3-only family, a large group of apoptosis-inducers such as Noxa, BBC3/Puma, BID and Bim. The BH3-only proteins 
interact with the anti-apoptotic BCL2-proteins thereby antagonizing their pro-survival function (Coultas and Strasser 2003; Shibue and Taniguchi 2006). Two models have been proposed for apoptosis induction by BH3-only proteins: In the "direct activator/derepressor model" (Kim et al, 2006) strong BH3-only proteins such as Bim, Puma and truncated BID act as direct activators of BAX, whereas in the "displacement model" (Labi et al, 2006; Willis et al, 2007) these three proteins are potent neutralizers of all five BCL2-like pro-survival proteins. Weak BH3-only proteins such as Noxa act as sensitizers by inactivating specific pro-survival BCL2-proteins. Oligomerization of BAX or Bak in the mitochondrial outer membrane causes release of Cytochrome-c from mitochondria. Cytochrome- $c$ binds to APAF1 that recruits Procaspase-9 and activates the so-called "apoptosome". Once activated Caspase- 8 and Caspase- 9 cleave the downstream effector Caspases-3 and -7 which provoke cellular destruction, nuclear DNA fragmentation and apoptotic cell death. In some cells, the two pathways intersect since Caspase- 8 can process the BCL2-family member BID into its active truncated form (Scaffidi et al, 1998) and thereby activate mitochondrial death signaling.

The activity of Caspases is counteracted by members of the inhibitor of apoptosis protein (IAP) family. In contrast to other IAPs (XIAP, c-IAP1, c-IAP2, NAIP) BIRC5/Survivin contains only a single baculovirus IAP repeat (BIR) and lacks the RING finger domain. Its apoptosis-protecting function therefore is still under debate: Survivin was shown to inhibit effector Caspases via its single BIR domain, but also to act upstream at the level of mitochondria (Shankar et al, 2001; Liu et al, 2004). Survivin is frequently expressed in various malignancies, among them neuroblastoma and leukemia (Adida et al, 1998; Adida et al, 2000; Granziero et al, 2001; Islam et al, 2000). In neuroblastoma the expression of Survivin has been reported to correlate with a reduced apoptotic index in vivo, with a shortened overall survival rate, an unfavorable prognosis and an increased relapse rate. We have shown that FOXO3 is an upstream regulator of Survivin in neuroblastoma and that Survivin is critical for sensitivity to chemotherapeutic agents (Obexer et al, 2009).

\section{Intrinsic death stimulus Extrinsic death signal}

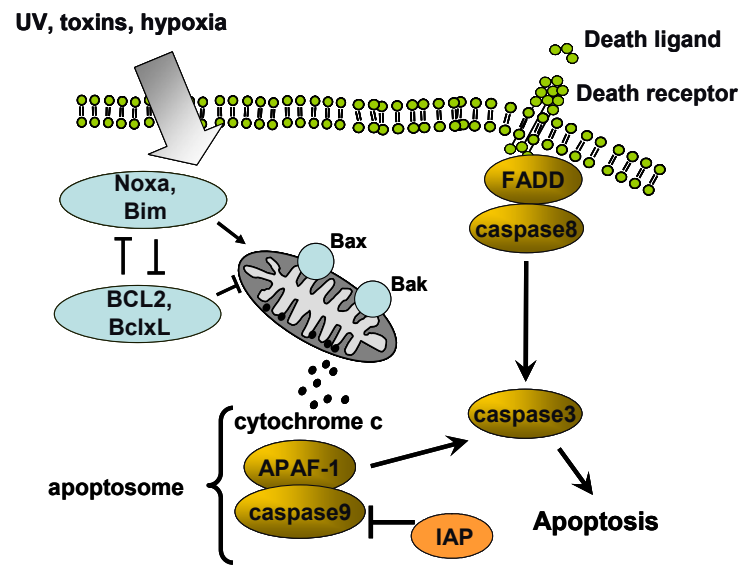

Fig. 3. Schematic presentation of "extrinsic" and "intrinsic" apoptosis signaling in mammalian cells. 


\subsubsection{FOXO3 in neuroblastoma cells}

In neuroblastoma tumors the PI3K/PKB signaling pathway is frequently hyperactivated which leads to proliferation and therapy resistance of the tumor cells. PTEN mutations are rare (below 10\%) in neuroblastoma but altered expression of PICT-1, a PTEN-stabilizing protein (Okahara et al, 2006) and aberrant neurotrophic factor signaling may be responsible for the hyperactivation of this signaling pathway. Hyperactivation of PKB was identified as a novel prognostic indicator for adverse clinical outcome and overall survival in neuroblastoma as it correlates with NMYC-amplification, 1p36 deletion, advanced disease stage, age at diagnosis and unfavorable histology (Opel et al, 2007). Several studies indicate that BDNF, by binding to its cognate receptor TrkB (BDNF and TrkB being markers for a poor 5-year survival outcome) increases neuroblastoma tumor cell survival (Feng et al, 2001; Matsumoto et al, 1995; Nakagawara et al, 1993), cell invasion (Matsumoto et al, 1995) and protects neuroblastoma cells from chemotherapy (Middlemas et al, 1999; Scala et al, 1996). BDNF promotes neurite extension (Nakagawara et al, 1993) and survival of sensory neurons (Acheson et al, 1995) under normal conditions. It was shown that the ability of BDNF to rescue neuroblastoma cells from chemotherapy-induced cell death was abrogated by the treatment with the tyrosine kinase inhibitor K252a or the PI3K-inhibitor Ly294002, indicating that both TrkB and PI3K activities are required for survival (Jaboin et al, 2002). In this context, the transcription factors FOXO1, FOXO3 and FOXO4 have been reported to be regulated downstream of Trk receptor signaling (Mai et al, 2002). They can induce apoptosis of cerebellar granule neurons (Brunet et al, 1999). In cortical neurons NGF, BDNF, NT-3 and NT-4 cause inactivation of FOXO3 by phosphorylation through PKB and SGK leading to neurotrophin-mediated cell survival of rat neurons. In concordance the PI3K inhibitor Ly294002 caused decreased phosphorylation of FOXO3 and induced cell death in these rat cells (Zheng et al, 2002). In SH-SY5Y neuroblastoma cells IGF-I signaling is associated with PKB-mediated phosphorylation of FOXO3 and its translocation into the cytoplasm. During growth factor withdrawal-induced apoptosis FOXO3 is imported into the nucleus in these cells (Schwab et al, 2005). Both, TrkB and BDNF may contribute to the chemoresistance of poor prognosis tumors and the suppression of PI3K activity or activation of further downstream targets of this pathway, such as FOXO3, could therefore significantly increase the effects of therapeutic agents on neuroblastoma tumors.

To analyze the connection between deregulated PI3K/PKB survival signaling and impaired apoptotic cell death in neuroblastoma, we determined the protein levels of PKB, FOXO3, phospho-PKB (serine-473) and phospho-FOXO3 (threonine-32) by immunoblot in different neuroblastoma cell lines and found that PKB and FOXO3 were phosphorylated, suggesting the inactivation of FOXO3. To study the function of FOXO3 we infected SH-EP and STANB15 neuroblastoma cells (Narath et al, 2007) with retroviruses coding for a $4 \mathrm{OH}$-tamoxifen (4OHT)-regulated FOXO3(A3)ER ${ }^{\mathrm{tm}}$ transgene. In the untreated condition this fusion protein is expressed in the cytoplasm. Upon addition of $4 \mathrm{OHT}$ it translocates into the nucleus and regulates FOXO3 target genes. Activation of FOXO3 in SH-EP/FOXO3 and NB15/FOXO3 cells promoted loss of mitochondrial activity, Cytochrome-c-release and Caspase-dependent apoptosis. FOXO3 induced TRAIL and the BH3-only proteins Noxa and Bim as measured by real time RT-PCR and immunoblot implicating both, extrinsic and intrinsic death pathways. However, expression of dominant negative FADD, which blocks the formation of the DISC and activation of Caspase-8, did not inhibit FOXO3-induced cell death, whereas transgenic expression of BCL2 protected against apoptosis. This excluded the death receptor pathway 
and suggested that cell death decision is regulated by BCL2-rheostat. Importantly, shRNAknockdown of the pro-apoptotic BH3-only proteins Noxa or Bim decreased apoptosis, indicating that Noxa and Bim cooperate to mediate FOXO3-induced cell death. In this work we described for the first time that Noxa and Bim establish a connection between FOXO3 and mitochondria and that both BH3-only proteins are critically involved in FOXO3induced apoptosis in neuroblastoma (Obexer et al, 2007). In a second paper we demonstrated for the first time that repression of the apoptosis inhibitor protein BIRC5/Survivin by FOXO3 sensitizes neuroblastoma cells to DNA-damage- and FOXO3mediated apoptosis. The survivin gene is located at 17q25 an area that is frequently altered in neuroblastoma. Gain of chromosome $17 \mathrm{q}$ or the distal translocation of $17 \mathrm{q}$ is of prognostic relevance and correlates with aggressive tumors (Islam et al, 2000). Since activated PKB protects neuroblastoma cells from chemotherapy-induced apoptosis and both, active PKB and Survivin are predictive for an adverse clinical outcome we analyzed a possible connection between PKB and Survivin. We found that inhibition of the PI3K/PKB signaling pathway by the PI3K-inhibitor Ly294002 induces nuclear accumulation of FOXO3 and subsequently represses the pro-survival protein Survivin. Conditional FOXO3 activation repressed Survivin transcription and protein expression. Since the repression of Survivin by FOXO3 can be blocked by cycloheximide we found that in neuroblastoma FOXO3 rather indirectly downregulates the survivin promoter activity. Transgenic Survivin expression exerted a significant anti-apoptotic effect and prevented the accumulation of Bim and BAX at the mitochondria, the loss of mitochondrial membrane potential as well as the release of Cytochrome-c during FOXO3-activation and significantly delayed apoptosis. In concordance, Survivin knockdown by retroviral shRNA-technology accelerated FOXO3induced apoptosis. In this paper we further demonstrated that low-level activation of FOXO3 sensitized neuroblastoma cells to the DNA-damaging agents doxorubicin and etoposide, whereas the overexpression of Survivin diminished FOXO3-sensitization to these drugs. These results suggest that repression of Survivin by FOXO3 facilitates FOXO3induced apoptosis and sensitizes neuroblastoma cells to apoptosis induced by DNAdamaging agents, which supports the central role of PI3K-PKB-FOXO3 signaling in drug resistance of human neuroblastoma (Obexer et al, 2009).

As FOXO3 induction seems to be beneficial for the treatment in neuroblastoma, we searched for natural compounds that might activate FOXO3. The phytochemical indol-3-carbinol (I3C) which derives from cruciferous vegetables, has been shown to induce cell cycle arrest and apoptosis by targeting BCL2 and the cyclin-dependent kinase inhibitor p27Kip1 in colon cancer cells (Aggarwal and Ichikawa 2005). In neuroblastoma cells I3C induces cell death in various cell lines, such as SH-EP, STA-NB1 and STA-NB15. I3C-mediated apoptosis can be blocked via the pan-Caspase-inhibitor zVAD and also via the Caspase-9 inhibitor LEHD demonstrating that I3C induces Caspases-dependent cell death (figure 4A). In SH-EP cells treatment with I3C induced the expression of the BH3-only proteins Noxa and Bim already 4 hours after I3Ctreatment and reduced the expression of Survivin after 8 hours (figure 4C). As all three proteins are transcriptional targets of FOXO3 we hypothesized that $\mathrm{I} 3 \mathrm{C}$ might induce the translocation and thereby activation of endogenous FOXO3 in neuroblastoma cells. To answer this question we generated SH-EP cells that express an enhanced cyan fluorescent protein (ECFP)-FOXO3 fusion protein which localizes to the cytoplasm in untreated cells. Already 30 minutes after I3C treatment FOXO3 shuttles into the nucleus and after 3 hours almost all cells show nuclear FOXO3 demonstrating that $\mathrm{I} 3 \mathrm{C}$ leads to FOXO3-activation (Figure 4B). 
A.)

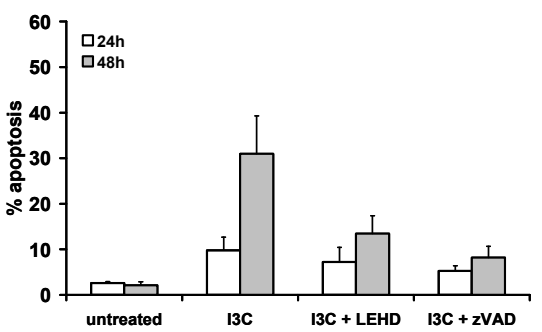

C.)

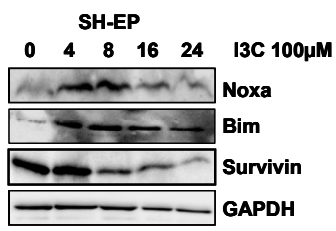

B.)

D.)
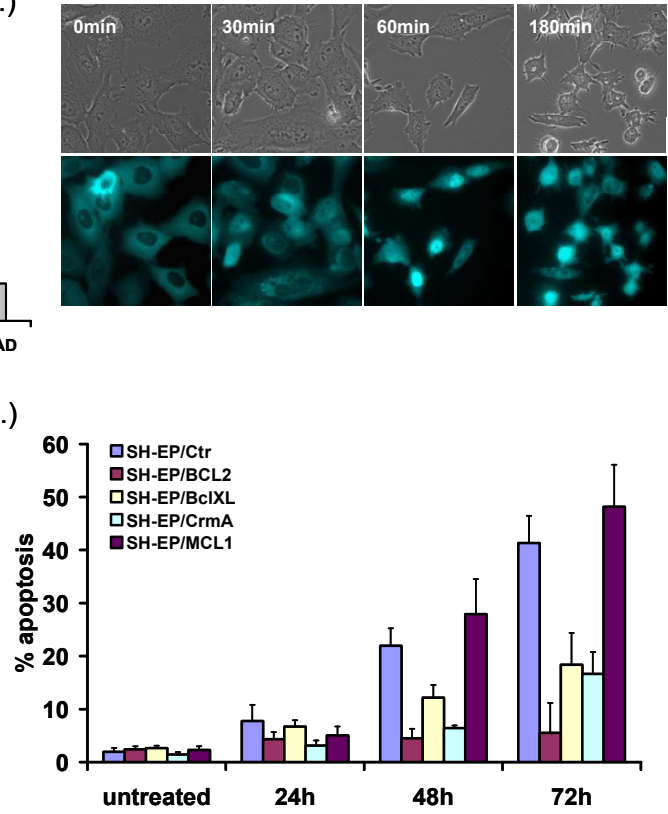

A) SH-EP cells were treated for 24 and 48 hours with I3C $(100 \mu \mathrm{M})$ alone or in combination with the Caspase-9 inhibitor LEHD, or the pan-Caspase-inhibitor zVAD. Apoptosis was determined by PI-FACS analysis. B) SH-EP cells were retrovirally infected with a plasmid coding for ECFP-FOXO3. Treatment of these SH-EP/ECFP-FOXO3 cells for 30, 60 and 180 minutes with $100 \mu \mathrm{M}$ I3C induced translocation of FOXO3 from the cytoplasm to the nucleus as analyzed by live cell fluorescence imaging in an Axiovert200M microscope (Zeiss). C) SH-EP cells were treated for 4, 8, 16 and 24 hours with $100 \mu \mathrm{M} \mathrm{I3C}$ and the expression of Noxa, Bim and Survivin was determined by immunoblot. GAPDH was used as loading control. D) SH-EP cells were retrovirally infected with plasmids coding for BCL2, BclxL, CrmA and MCL1. These transgenic cell lines were treated for 24,48 and 72 hours with $100 \mu \mathrm{M} \mathrm{I3C}$ and apoptosis was analyzed by PI-FACS-analysis.

Fig. 4. I3C activates FOXO3 and induces apoptosis in neuroblastoma cells.

Similar to FOXO3-induced apoptosis also I3C-mediated cell death is inhibited by the prosurvival proteins BCL-2 and BclxL implicating that BCL2-rheostat is essential for the control of I3C-induced apoptosis (Obexer et al, 2007). In addition, ectopic expression of CrmA, a Caspase-8 inhibitor of the Cowpox virus, reduced I3C-induced apoptosis suggesting that active Caspase- 3 might cleave Caspase- 8 and thereby initiate a deathinducing feedback loop. This is also consistent with FOXO3-induced cell death in neuroblastoma cells. Ectopic expression of the pro-survival protein MCL1 had no effect on I3C-mediated apoptosis (figure 4D). The combined results implicate that I3C induces apoptosis at least in part via induction of FOXO3 which in turn activates the BH3-only proteins Bim and Noxa and represses the anti-apoptotic protein Survivin. As inactivation of FOXO3 in malignant neuroblastoma cells critically contributes to apoptosis resistance, strategies to activate FOXO3 in neuroblastoma despite aberrant PKB-signaling, for example by I3C and thereby to restore the function of a deregulated PKB-FOXO3 pathway, may improve the therapy of this malignant disease. 


\section{Conclusions: FOXO3 - a double-edged sword in therapeutic intervention}

FOXO transcription factors were originally identified as tumor suppressor proteins that, when activated or overexpressed in tumor cells, trigger the expression of apoptosis-inducers of the BCL2-family or of the death ligand family. FOXOs integrate a plethora of different signals and translate them into complex, cell-type dependent gene expression patterns. Their transcriptional targets regulate cell cycle arrest and cell death, but may also promote stress resistance and longevity. Therefore the effects of FOXO3 activation might completely differ between different tumor types, but also between differentiation stages of cancer cells within one tumor. This is in particular of importance in human neuroblastoma, which frequently contain tumor cells of various differentiation states. Although in experimental systems with relatively homogenous cell populations FOXO3 is an efficient killer of neuroblastoma cells, the in vivo situation might completely differ and active FOXO3 may even support the survival of specific subpopulations of cancer-initiating cells during chemotherapy. The immunesuppressive function of FOXO3 adds an additional level of complexity in the role of FOXOs during cancer development and cancer surveillance. In particular in high-stage neuroblastoma, where immune infiltrations are almost absent, the activation of FOXO3 in immune cells, possibly as an unwanted side-effect of chemotherapy, may shut down tumorspecific cytotoxic immune responses. Therefore it has to be carefully investigated for which specific subtype of cancer FOXO3 is an attractive target and whether the inhibition of FOXO3 in immune cells may boost anti-cancer immune responses. So this double-edged sword has to be manipulated and handled with care otherwise it will cause detrimental damage.

\section{References}

Acheson, A., Conover J. C., Fandl J. P., DeChiara T. M., Russell M., Thadani A., Squinto S. P., Yancopoulos G. D. and Lindsay R. M. (1995). A BDNF autocrine loop in adult sensory neurons prevents cell death. Nature 374, 450-453.

Adida, C., Berrebi D., Peuchmaur M., Reyes-Mugica M. and Altieri D. C. (1998). Antiapoptosis gene, survivin, and prognosis of neuroblastoma. Lancet 351, 882-883.

Adida, C., Recher C., Raffoux E., Daniel M. T., Taksin A. L., Rousselot P., Sigaux F., Degos L., Altieri D. C. and Dombret H. (2000). Expression and prognostic significance of survivin in de novo acute myeloid leukaemia. Br. J. Haematol. 111, 196-203.

Aggarwal, B. B. and Ichikawa H. (2005). Molecular targets and anticancer potential of indole-3-carbinol and its derivatives. Cell Cycle 4, 1201-1215.

Alvarez, B., Martinez A., Burgering B. M. and Carrera A. C. (2001). Forkhead transcription factors contribute to execution of the mitotic programme in mammals. Nature 413, 744-747.

Arden, K. C. (2008a). FOXO animal models reveal a variety of diverse roles for FOXO transcription factors. Oncogene 27, 2345-2350.

Arden, K. C. (2008b). FOXO animal models reveal a variety of diverse roles for FOXO transcription factors. Oncogene 27, 2345-2350.

Arnold, C. P., Tan R., Zhou B., Yue S. B., Schaffert S., Biggs J. R., Doyonnas R., Lo M. C., Perry J. M., Renault V. M. et al. (2011). MicroRNA programs in normal and aberrant stem and progenitor cells. Genome Res. 21, 798-810. 
Bakker, W. J., Harris I. S. and Mak T. W. (2007). FOXO3a is activated in response to hypoxic stress and inhibits HIF1-induced apoptosis via regulation of CITED2. Mol. Cell 28, 941-953.

Biggs, W. H., Meisenhelder J., Hunter T., Cavenee W. K. and Arden K. C. (1999). Protein kinase B/Akt-mediated phosphorylation promotes nuclear exclusion of the winged helix transcription factor FKHR1. Proc. Natl. Acad. Sci. U. S. A 96, 7421-7426.

Bond, J., Roberts E., Mochida G. H., Hampshire D. J., Scott S., Askham J. M., Springell K., Mahadevan M., Crow Y. J., Markham A. F. et al. (2002). ASPM is a major determinant of cerebral cortical size. Nat. Genet. 32, 316-320.

Brett, J. O., Renault V. M., Rafalski V. A., Webb A. E. and Brunet A. (2011). The microRNA cluster miR-106b 25 regulates adult neural stem/progenitor cell proliferation and neuronal differentiation. Aging 3, 108-124.

Brunet, A., Bonni A., Zigmond M. J., Lin M. Z., Juo P., Hu L. S., Anderson M. J., Arden K. C., Blenis J. and Greenberg M. E. (1999). Akt promotes cell survival by phosphorylating and inhibiting a Forkhead transcription factor. Cell 96, 857-868.

Brunet, A., Sweeney L. B., Sturgill J. F., Chua K. F., Greer P. L., Lin Y., Tran H., Ross S. E., Mostoslavsky R., Cohen H. Y. et al. (2004). Stress-dependent regulation of FOXO transcription factors by the SIRT1 deacetylase. Science 303, 2011-2015.

Calnan, D. R. and Brunet A. (2008). The FoxO code. Oncogene 27, 2276-2288.

Carlsson, P. and Mahlapuu M. (2002). Forkhead transcription factors: key players in development and metabolism. Dev. Biol. 250, 1-23.

Castrillon, D. H., Miao L., Kollipara R., Horner J. W. and DePinho R. A. (2003). Suppression of ovarian follicle activation in mice by the transcription factor Foxo3a. Science 301, 215-218.

Chen, J., Gomes A. R., Monteiro L. J., Wong S. Y., Wu L. H., Ng T. T., Karadedou C. T., Millour J., Ip Y. C., Cheung Y. N. et al. (2010). Constitutively Nuclear FOXO3a Localization Predicts Poor Survival and Promotes Akt Phosphorylation in Breast Cancer. Plos One 5.

Chong, Z. Z., Li F. and Maiese K. (2005). Oxidative stress in the brain: novel cellular targets that govern survival during neurodegenerative disease. Prog. Neurobiol. 75, 207-246.

Coffer, P. J. and Burgering B. M. (2004). Forkhead-box transcription factors and their role in the immune system. Nat. Rev. Immunol. 4, 889-899.

Cory, S. and Adams J. M. (2002). The Bcl2 family: regulators of the cellular life-or-death switch. Nat. Rev. Cancer 2, 647-656.

Coultas, L. and Strasser A. (2003). The role of the Bcl-2 protein family in cancer. Semin. Cancer Biol. 13, 115-123.

Dejean, A. S., Beisner D. R., Ch'en I. L., Kerdiles Y. M., Babour A., Arden K. C., Castrillon D. H., DePinho R. A. and Hedrick S. M. (2009). Transcription factor Foxo3 controls the magnitude of $\mathrm{T}$ cell immune responses by modulating the function of dendritic cells. Nat. Immunol. 10, 504-513.

Dijkers, P. F., Medema R. H., Lammers J. W. J., Koenderman L. and Coffer P. J. (2000a). Expression of the pro-apoptotic Bcl-2 family member Bim is regulated by the forkhead transcription factor FKHR-L1. Current Biology 10, 1201-1204. 
Dijkers, P. F., Medema R. H., Pals C., Banerji L., Thomas N. S., Lam E. W., Burgering B. M., Raaijmakers J. A., Lammers J. W., Koenderman L. et al. (2000b). Forkhead transcription factor FKHR-L1 modulates cytokine-dependent transcriptional regulation of p27(KIP1). Mol. Cell Biol. 20, 9138-9148.

Essers, M. A., Vries-Smits L. M., Barker N., Polderman P. E., Burgering B. M. and Korswagen H. C. (2005). Functional interaction between beta-catenin and FOXO in oxidative stress signaling. Science 308, 1181-1184.

Essers, M. A., Weijzen S., Vries-Smits A. M., Saarloos I., de Ruiter N. D., Bos J. L. and Burgering B. M. (2004). FOXO transcription factor activation by oxidative stress mediated by the small GTPase Ral and JNK. EMBO J. 23, 4802-4812.

Feng, X., Jiang H., Baik J. C., Edgar C. and Eide F. F. (2001). BDNF dependence in neuroblastoma. J. Neurosci. Res. 64, 355-363.

Fernandez, d. M., Essafi A., Soeiro I., Pietersen A. M., Birkenkamp K. U., Edwards C. S., Martino A., Nelson B. H., Francis J. M., Jones M. C. et al. (2004). FoxO3a and BCRABL regulate cyclin D2 transcription through a STAT5/BCL6-dependent mechanism. Mol. Cell Biol. 24, 10058-10071.

Fukunaga, K., Ishigami T. and Kawano T. (2005). Transcriptional regulation of neuronal genes and its effect on neural functions: expression and function of forkhead transcription factors in neurons. J. Pharmacol. Sci. 98, 205-211.

Furukawa-Hibi, Y., Yoshida-Araki K., Ohta T., Ikeda K. and Motoyama N. (2002). FOXO forkhead transcription factors induce $\mathrm{G}(2)-\mathrm{M}$ checkpoint in response to oxidative stress. J. Biol. Chem. 277, 26729-26732.

Furuyama, T., Nakazawa T., Nakano I. and Mori N. (2000). Identification of the differential distribution patterns of mRNAs and consensus binding sequences for mouse DAF16 homologues. Biochem. J. 349, 629-634.

Gan, L., Zheng W., Chabot J. G., Unterman T. G. and Quirion R. (2005). Nuclear/cytoplasmic shuttling of the transcription factor FoxO1 is regulated by neurotrophic factors. J. Neurochem. 93, 1209-1219.

Gilley, J., Coffer P. J. and Ham J. (2003). FOXO transcription factors directly activate bim gene expression and promote apoptosis in sympathetic neurons. J. Cell Biol. 162, 613-622.

Granziero, L., Ghia P., Circosta P., Gottardi D., Strola G., Geuna M., Montagna L., Piccoli P., Chilosi M. and Caligaris-Cappio F. (2001). Survivin is expressed on CD40 stimulation and interfaces proliferation and apoptosis in B-cell chronic lymphocytic leukemia. Blood 97, 2777-2783.

Harada, Y., Harada Y., Elly C., Ying G., Paik J. H., DePinho R. A. and Liu Y. C. (2010). Transcription factors Foxo3a and Foxo1 couple the E3 ligase Cbl-b to the induction of Foxp3 expression in induced regulatory T cells. Journal of Experimental Medicine 207, 1381-1391.

Hosaka, T., Biggs W. H., III, Tieu D., Boyer A. D., Varki N. M., Cavenee W. K. and Arden K. C. (2004). Disruption of forkhead transcription factor (FOXO) family members in mice reveals their functional diversification. Proc. Natl. Acad. Sci. U. S. A 101, 29752980. 
Hu, M. C., Lee D. F., Xia W., Golfman L. S., Ou-Yang F., Yang J. Y., Zou Y., Bao S., Hanada N., Saso H. et al. (2004). IkappaB kinase promotes tumorigenesis through inhibition of forkhead FOXO3a. Cell 117, 225-237.

Hui, R. C., Francis R. E., Guest S. K., Costa J. R., Gomes A. R., Myatt S. S., Brosens J. J. and Lam E. W. (2008a). Doxorubicin activates FOXO3a to induce the expression of multidrug resistance gene ABCB1 (MDR1) in K562 leukemic cells. Mol. Cancer Ther. 7, 670-678.

Hui, R. C., Gomes A. R., Constantinidou D., Costa J. R., Karadedou C. T., Fernandez de M. S., Wymann M. P., Brosens J. J., Schulze A. and Lam E. W. (2008b). The forkhead transcription factor FOXO3a increases phosphoinositide-3 kinase/Akt activity in drug-resistant leukemic cells through induction of PIK3CA expression. Mol. Cell Biol. 28, 5886-5898.

Islam, A., Kageyama H., Takada N., Kawamoto T., Takayasu H., Isogai E., Ohira M., Hashizume K., Kobayashi H., Kaneko Y. et al. (2000). High expression of Survivin, mapped to $17 \mathrm{q} 25$, is significantly associated with poor prognostic factors and promotes cell survival in human neuroblastoma. Oncogene 19, 617-623.

Jaboin, J., Kim C. J., Kaplan D. R. and Thiele C. J. (2002). Brain-derived neurotrophic factor activation of TrkB protects neuroblastoma cells from chemotherapy-induced apoptosis via phosphatidylinositol 3'-kinase pathway. Cancer Res. 62, 6756-6763.

Katoh, M. and Katoh M. (2004). Human FOX gene family (Review). Int. J. Oncol. 25, 14951500.

Kim, H., Rafiuddin-Shah M., Tu H. C., Jeffers J. R., Zambetti G. P., Hsieh J. J. and Cheng E. H. (2006). Hierarchical regulation of mitochondrion-dependent apoptosis by BCL-2 subfamilies. Nat. Cell Biol. 8, 1348-1358.

Kops, G. J., Dansen T. B., Polderman P. E., Saarloos I., Wirtz K. W., Coffer P. J., Huang T. T., Bos J. L., Medema R. H. and Burgering B. M. (2002a). Forkhead transcription factor FOXO3a protects quiescent cells from oxidative stress. Nature 419, 316-321.

Kops, G. J. P. L., Medema R. H., Glassford J., Essers M. A. G., Dijkers P. F., Coffer P. J., Lam E. W. F. and Burgering B. M. T. (2002b). Control of cell cycle exit and entry by protein kinase B-regulated Forkhead transcription factors. Molecular and Cellular Biology 22, 2025-2036.

Labi, V., Erlacher M., Kiessling S. and Villunger A. (2006). BH3-only proteins in cell death initiation, malignant disease and anticancer therapy. Cell Death. Differ. 13, 13251338 .

Lal, A. and Gorospe M. (2006). Egad, more forms of gene regulation: the gadd45a story. Cell Cycle 5, 1422-1425.

Lee, K. S., Iijima-Ando K., Iijima K., Lee W. J., Lee J. H., Yu K. and Lee D. S. (2009). JNK/FOXO-mediated neuronal expression of fly homologue of peroxiredoxin II reduces oxidative stress and extends life span. J. Biol. Chem. 284, 29454-29461.

Lehtinen, M. K., Yuan Z., Boag P. R., Yang Y., Villen J., Becker E. B., DiBacco S., de 1., I, Gygi S., Blackwell T. K. et al. (2006). A conserved MST-FOXO signaling pathway mediates oxidative-stress responses and extends life span. Cell 125, 987-1001. 
Leisser, C., Rosenberger G., Maier S., Fuhrmann G., Grusch M., Strasser S., Huettenbrenner S., Fassl S., Polgar D., Krieger S. et al. (2004). Subcellular localisation of Cdc25A determines cell fate. Cell Death. Differ. 11, 80-89.

Li, J., Yen C., Liaw D., Podsypanina K., Bose S., Wang S. I., Puc J., Miliaresis C., Rodgers L., McCombie R. et al. (1997). PTEN, a putative protein tyrosine phosphatase gene mutated in human brain, breast, and prostate cancer. Science 275, 1943-1947.

Lin, K., Dorman J. B., Rodan A. and Kenyon C. (1997). daf-16: An HNF-3/forkhead family member that can function to double the life-span of Caenorhabditis elegans. Science $278,1319-1322$.

Lin, L., Hron J. D. and Peng S. L. (2004). Regulation of NF-kappaB, Th activation, and autoinflammation by the forkhead transcription factor Foxo3a. Immunity. 21, 203213.

Liu, T., Brouha B. and Grossman D. (2004). Rapid induction of mitochondrial events and caspase-independent apoptosis in Survivin-targeted melanoma cells. Oncogene 23, 39-48.

Mai, L., Jope R. S. and Li X. (2002). BDNF-mediated signal transduction is modulated by GSK3beta and mood stabilizing agents. J. Neurochem. 82, 75-83.

Matsumoto, K., Wada R. K., Yamashiro J. M., Kaplan D. R. and Thiele C. J. (1995). Expression of brain-derived neurotrophic factor and p145TrkB affects survival, differentiation, and invasiveness of human neuroblastoma cells. Cancer Res. 55, 1798-1806.

Mei, Y., Zhang Y., Yamamoto K., Xie W., Mak T. W. and You H. (2009). FOXO3a-dependent regulation of Pink1 (Park6) mediates survival signaling in response to cytokine deprivation. Proc. Natl. Acad. Sci. U. S. A 106, 5153-5158.

Middlemas, D. S., Kihl B. K., Zhou J. and Zhu X. (1999). Brain-derived neurotrophic factor promotes survival and chemoprotection of human neuroblastoma cells. J. Biol. Chem. 274, 16451-16460.

Miyaguchi, Y., Tsuchiya K. and Sakamoto K. (2009). P53 negatively regulates the transcriptional activity of FOXO3a under oxidative stress. Cell Biol. Int. 33, 853-860.

Miyamoto, K., Araki K. Y., Naka K., Arai F., Takubo K., Yamazaki S., Matsuoka S., Miyamoto T., Ito K., Ohmura M. et al. (2007). Foxo3a is essential for maintenance of the hematopoietic stem cell pool. Cell Stem Cell 1, 101-112.

Modur, V., Nagarajan R., Evers B. M. and Milbrandt J. (2002). FOXO proteins regulate tumor necrosis factor-related apoptosis inducing ligand expression. Implications for PTEN mutation in prostate cancer. J. Biol. Chem. 277, 47928-47937.

Naka, K., Hoshii T., Muraguchi T., Tadokoro Y., Ooshio T., Kondo Y., Nakao S., Motoyama N. and Hirao A. (2010). TGF-beta-FOXO signalling maintains leukaemia-initiating cells in chronic myeloid leukaemia. Nature 463, 676-680.

Nakagawara, A., Arima-Nakagawara M., Scavarda N. J., Azar C. G., Cantor A. B. and Brodeur G. M. (1993). Association between high levels of expression of the TRK gene and favorable outcome in human neuroblastoma. N. Engl. J. Med. 328, 847-854.

Narath, R., Ambros I. M., Kowalska A., Bozsaky E., Boukamp P. and Ambros P. F. (2007). Induction of senescence in $\mathrm{MYCN}$ amplified neuroblastoma cell lines by hydroxyurea. Genes Chromosomes. Cancer 46, 130-142. 
Obexer, P., Geiger K., Ambros P. F., Meister B. and Ausserlechner M. J. (2007). FKHRL1mediated expression of Noxa and Bim induces apoptosis via the mitochondria in neuroblastoma cells. Cell Death. Differ. 14, 534-547.

Obexer, P., Hagenbuchner J., Unterkircher T., Sachsenmaier N., Seifarth C., Bock G., Porto V., Geiger K. and Ausserlechner M. (2009). Repression of BIRC5/Survivin by FOXO3/FKHRL1 Sensitizes Human Neuroblastoma Cells to DNA-Damageinduced Apoptosis. Mol. Biol. Cell.

Obsil T and Obsilova V. Structural basis for DNA recognition by FOXO proteins. Biochim Biophys Acta 71(3), 946-954. 2010.

Okahara, F., Itoh K., Nakagawara A., Murakami M., Kanaho Y. and Maehama T. (2006). Critical role of PICT-1, a tumor suppressor candidate, in phosphatidylinositol 3,4,5trisphosphate signals and tumorigenic transformation. Mol. Biol. Cell 17, 4888-4895.

Opel, D., Poremba C., Simon T., Debatin K. M. and Fulda S. (2007). Activation of Akt predicts poor outcome in neuroblastoma. Cancer Res. 67, 735-745.

Paik, J. H., Ding Z., Narurkar R., Ramkissoon S., Muller F., Kamoun W. S., Chae S. S., Zheng H., Ying H., Mahoney J. et al. (2009). FoxOs cooperatively regulate diverse pathways governing neural stem cell homeostasis. Cell Stem Cell 5, 540-553.

Paik, J. H., Kollipara R., Chu G., Ji H., Xiao Y., Ding Z., Miao L., Tothova Z., Horner J. W., Carrasco D. R. et al. (2007). FoxOs are lineage-restricted redundant tumor suppressors and regulate endothelial cell homeostasis. Cell 128, 309-323.

Pandiyan, P., Gartner D., Soezeri O., Radbruch A., Schulze-Osthoff K. and BrunnerWeinzierl M. C. (2004). CD152 (CTLA-4) determines the unequal resistance of Th1 and Th2 cells against activation-induced cell death by a mechanism requiring PI3 kinase function. J. Exp. Med. 199, 831-842.

Peltier, J., O'Neill A. and Schaffer D. V. (2007). PI3K/Akt and CREB regulate adult neural hippocampal progenitor proliferation and differentiation. Dev. Neurobiol. 67, 13481361.

Pirianov, G., Brywe K. G., Mallard C., Edwards A. D., Flavell R. A., Hagberg H. and Mehmet H. (2007). Deletion of the c-Jun N-terminal kinase 3 gene protects neonatal mice against cerebral hypoxic-ischaemic injury. J. Cereb. Blood Flow Metab 27, 1022-1032.

Ramaswamy, S., Nakamura N., Sansal I., Bergeron L. and Sellers W. R. (2002). A novel mechanism of gene regulation and tumor suppression by the transcription factor FKHR. Cancer Cell 2, 81-91.

Rena, G., Woods Y. L., Prescott A. R., Peggie M., Unterman T. G., Williams M. R. and Cohen P. (2002). Two novel phosphorylation sites on FKHR that are critical for its nuclear exclusion. EMBO J. 21, 2263-2271.

Renault, V. M., Rafalski V. A., Morgan A. A., Salih D. A., Brett J. O., Webb A. E., Villeda S. A., Thekkat P. U., Guillerey C., Denko N. C. et al. (2009). FoxO3 regulates neural stem cell homeostasis. Cell Stem Cell 5, 527-539.

Riou, C., Yassine-Diab B., Van grevenynghe J., Somogyi R., Greller L. D., Gagnon D., Gimmig S., Wilkinson P., Shi Y., Cameron M. J. et al. (2007). Convergence of TCR and cytokine signaling leads to FOXO3a phosphorylation and drives the survival of CD4+ central memory T cells. J. Exp. Med. 204, 79-91. 
Sakai, A., Thieblemont C., Wellmann A., Jaffe E. S. and Raffeld M. (1998). PTEN gene alterations in lymphoid neoplasms. Blood 92, 3410-3415.

Scaffidi, C., Fulda S., Srinivasan A., Friesen C., Li F., Tomaselli K. J., Debatin K. M., Krammer P. H. and Peter M. E. (1998). Two CD95 (APO-1/Fas) signaling pathways. EMBO J. 17, 1675-1687.

Scala, S., Wosikowski K., Giannakakou P., Valle P., Biedler J. L., Spengler B. A., Lucarelli E., Bates S. E. and Thiele C. J. (1996). Brain-derived neurotrophic factor protects neuroblastoma cells from vinblastine toxicity. Cancer Res. 56, 3737-3742.

Schmidt, M., Fernandez d. M., van der H. A., Klompmaker R., Kops G. J., Lam E. W., Burgering B. M. and Medema R. H. (2002). Cell cycle inhibition by FoxO forkhead transcription factors involves downregulation of cyclin D. Mol. Cell Biol. 22, 78427852.

Schwab, T. S., Madison B. B., Grauman A. R. and Feldman E. L. (2005). Insulin-like growth factor-I induces the phosphorylation and nuclear exclusion of forkhead transcription factors in human neuroblastoma cells. Apoptosis. 10, 831-840.

Seoane, J., Le H. V., Shen L., Anderson S. A. and Massague J. (2004). Integration of Smad and forkhead pathways in the control of neuroepithelial and glioblastoma cell proliferation. Cell 117, 211-223.

Shankar, S. L., Mani S., O'Guin K. N., Kandimalla E. R., Agrawal S. and Shafit-Zagardo B. (2001). Survivin inhibition induces human neural tumor cell death through caspase-independent and -dependent pathways. J. Neurochem. 79, 426-436.

Shibue, T. and Taniguchi T. (2006). BH3-only proteins: Integrated control point of apoptosis. Int. J. Cancer 119, 2036-2043.

Siegrist,S.E., Hague,N.S., Chen,C.H., Hay,B.A. and Hariharan,I.K. (2010). Inactivation of Both foxo and reaper Promotes Long-Term Adult Neurogenesis in Drosophila. Current Biology 20, 643-648

Storz, P., Doppler H., Copland J. A., Simpson K. J. and Toker A. (2009). FOXO3a promotes tumor cell invasion through the induction of matrix metalloproteinases. Mol. Cell Biol. 29, 4906-4917.

Sunters, A., Madureira P. A., Pomeranz K. M., Aubert M., Brosens J. J., Cook S. J., Burgering B. M., Coombes R. C. and Lam E. W. (2006). Paclitaxel-induced nuclear translocation of FOXO3a in breast cancer cells is mediated by c-Jun NH2-terminal kinase and Akt. Cancer Res. 66, 212-220.

Tang, T. T., Dowbenko D., Jackson A., Toney L., Lewin D. A., Dent A. L. and Lasky L. A. (2002). The forkhead transcription factor AFX activates apoptosis by induction of the BCL-6 transcriptional repressor. J. Biol. Chem. 277, 14255-14265.

Tothova, Z., Kollipara R., Huntly B. J., Lee B. H., Castrillon D. H., Cullen D. E., McDowell E. P., Lazo-Kallanian S., Williams I. R., Sears C. et al. (2007b). FoxOs are critical mediators of hematopoietic stem cell resistance to physiologic oxidative stress. Cell $128,325-339$.

Tothova, Z., Kollipara R., Huntly B. J., Lee B. H., Castrillon D. H., Cullen D. E., McDowell E. P., Lazo-Kallanian S., Williams I. R., Sears C. et al. (2007a). FoxOs are critical mediators of hematopoietic stem cell resistance to physiologic oxidative stress. Cell $128,325-339$. 
Tran, H., Brunet A., Grenier J. M., Datta S. R., Fornace A. J., Jr., DiStefano P. S., Chiang L. W. and Greenberg M. E. (2002). DNA repair pathway stimulated by the forkhead transcription factor FOXO3a through the Gadd45 protein. Science 296, 530-534.

van der Horst A., Vries-Smits A. M., Brenkman A. B., van Triest M. H., van den B. N., Colland F., Maurice M. M. and Burgering B. M. (2006). FOXO4 transcriptional activity is regulated by monoubiquitination and USP7/HAUSP. Nat. Cell Biol. 8, 1064-1073.

van der Vos, K. E. and Coffer P. J. (2008). FOXO-binding partners: it takes two to tango. Oncogene 27, 2289-2299.

Wang F, Chan CH, Chen K, Guan X, Lin HK and Tong Q. Deacetylation of FOXO3 by SIRT1 or SIRT2 leads to Skp2-mediated FOXO3 ubiquitination and degradation. Oncogene , 1-12. 2011.

Wang, S. T., Chang C. C., Yen M. C., Tu C. F., Chu C. L., Peng Y. T., Chen D. Y., Lan J. L. and Lin C. C. (2011). RNA interference-mediated silencing of Foxo3 in antigenpresenting cells as a strategy for the enhancement of DNA vaccine potency. Gene Ther. 18, 372-383.

Watkins, S. K., Zhu Z. Q., Riboldi E., Shafer-Weaver K. A., Stagliano K. E. R., Sklavos M. M., Ambs S., Yagita H. and Hurwitz A. A. (2011). FOXO3 programs tumor-associated DCs to become tolerogenic in human and murine prostate cancer. Journal of Clinical Investigation 121, 1361-1372.

Weigelt, J., Climent I., Dahlman-Wright K. and Wikstrom M. (2001). Solution structure of the DNA binding domain of the human forkhead transcription factor AFX (FOXO4). Biochemistry 40, 5861-5869.

Willis, S. N., Fletcher J. I., Kaufmann T., van Delft M. F., Chen L., Czabotar P. E., Ierino H., Lee E. F., Fairlie W. D., Bouillet P. et al. (2007). Apoptosis initiated when BH3 ligands engage multiple Bcl-2 homologs, not Bax or Bak. Science 315, 856-859.

Won, C. K., Ji H. H. and Koh P. O. (2006). Estradiol prevents the focal cerebral ischemic injury-induced decrease of forkhead transcription factors phosphorylation. Neurosci. Lett. 398, 39-43.

Woods, Y. L., Rena G., Morrice N., Barthel A., Becker W., Guo S., Unterman T. G. and Cohen P. (2001). The kinase DYRK1A phosphorylates the transcription factor FKHR at Ser329 in vitro, a novel in vivo phosphorylation site. Biochem. J. 355, 597-607.

Xiao, L., Chen D., Hu P., Wu J., Liu W., Zhao Y., Cao M., Fang Y., Bi W., Zheng Z. et al. (2011). The c-Abl-MST1 Signaling Pathway Mediates Oxidative Stress-Induced Neuronal Cell Death. J. Neurosci. 31, 9611-9619.

Xuan, Z. and Zhang M. Q. (2005). From worm to human: bioinformatics approaches to identify FOXO target genes. Mech. Ageing Dev. 126, 209-215.

Yamada, K. M. and Araki M. (2001). Tumor suppressor PTEN: modulator of cell signaling, growth, migration and apoptosis. J. Cell Sci. 114, 2375-2382.

Yano, S., Morioka M., Fukunaga K., Kawano T., Hara T., Kai Y., Hamada J., Miyamoto E. and Ushio Y. (2001). Activation of Akt/protein kinase B contributes to induction of ischemic tolerance in the CA1 subfield of gerbil hippocampus. J. Cereb. Blood Flow Metab 21, 351-360. 
Zheng, W. H., Kar S. and Quirion R. (2000). Insulin-like growth factor-1-induced phosphorylation of the forkhead family transcription factor FKHRL1 is mediated by Akt kinase in PC12 cells. J. Biol. Chem. 275, 39152-39158.

Zheng, W. H., Kar S. and Quirion R. (2002). FKHRL1 and its homologs are new targets of nerve growth factor Trk receptor signaling. J. Neurochem. 80, 1049-1061. 


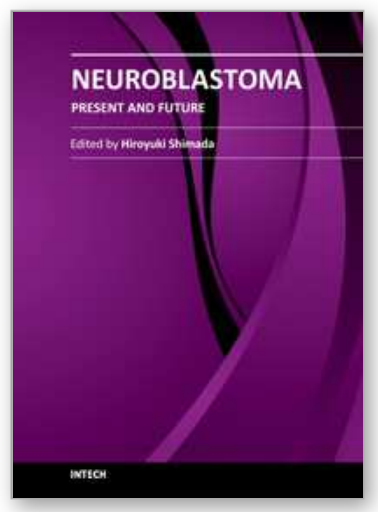

\author{
Neuroblastoma - Present and Future \\ Edited by Prof. Hiroyuki Shimada
}

ISBN 978-953-307-016-2

Hard cover, 366 pages

Publisher InTech

Published online 08, February, 2012

Published in print edition February, 2012

Neuroblastoma, once called "enigmatic", due to "unpredictable" clinical behaviors, is composed of biologically diverse tumors. Molecular/genomic properties unique to the individual tumors closely link to the clinical outcomes of patients. Establishing risk stratification models after analyzing biologic characteristics of each case has made a great success in patient management. However, the trend of improving survival rates in neuroblastoma over the last 30 years has started to level off, and currently available treatment modalities have almost reached to their maximized intensity. Furthermore, aggressive treatment causes significant long-term morbidities to the survivors. We really need to make the next step to the level of personalized medicine with more precise understanding of neuroblastoma biology. This book includes useful data and insights from the world's experts in this field. I believe this book can make an excellent contribution to all the investigators working hard and fighting for the children stricken by this disease.

\title{
How to reference
}

In order to correctly reference this scholarly work, feel free to copy and paste the following:

Michael J. Ausserlechner, Judith Hagenbuchner, Stefan Fuchs, Kathrin Geiger and Petra Obexer (2012). FOXO Transcription Factors as Potential Therapeutic Targets in Neuroblastoma, Neuroblastoma - Present and Future, Prof. Hiroyuki Shimada (Ed.), ISBN: 978-953-307-016-2, InTech, Available from:

$\mathrm{http}: / / \mathrm{www}$.intechopen.com/books/neuroblastoma-present-and-future/foxo-transcription-factors-as-potentialtherapeutic-targets-in-neuroblastoma

\section{INTECH}

open science | open minds

\section{InTech Europe}

University Campus STeP Ri

Slavka Krautzeka 83/A

51000 Rijeka, Croatia

Phone: +385 (51) 770447

Fax: +385 (51) 686166

www.intechopen.com

\section{InTech China}

Unit 405, Office Block, Hotel Equatorial Shanghai

No.65, Yan An Road (West), Shanghai, 200040, China

中国上海市延安西路65号上海国际贵都大饭店办公楼405单元

Phone: +86-21-62489820

Fax: $+86-21-62489821$ 
(C) 2012 The Author(s). Licensee IntechOpen. This is an open access article distributed under the terms of the Creative Commons Attribution 3.0 License, which permits unrestricted use, distribution, and reproduction in any medium, provided the original work is properly cited. 